\title{
UTILIZATION OF DRINKING WATER TREATMENT SLUDGE TO PRODUCE ALUMINUM SULFATE
}

\author{
Abd EL- Razek, T. M. ${ }^{(1)}$; Elgendy, A. S. ${ }^{(1)}$ and Fouad, M. M. ${ }^{(2)}$ \\ 1) Institute for Environmental Studies and Research, Ain Shams University \\ 2) Graduate student Quality and Environmental Affairs Department, Holding \\ Company for Water and Wastewater.
}

\begin{abstract}
In Egypt, water treatment industry consumes about 365,000 tons of aluminum sulfate as coagulant and produces more than 100 million tons of semidried sludge per year. The common disposal system of alum sludge in Egypt is to discharge it into natural water bodies. Toxic nature of free and complexed aluminum species to aquatic life, stringent environmental regulations on disposal of sludge into water bodies and costs of the chemicals used in water treatment process and sludge treatment led to evaluate coagulant recovery and subsequent reuse. The present work aimed at aluminum metal recovery from sludge obtained from El-Shiekh Zayd water treatment plant by acidification method to produce aluminum sulfate coagulant. Sludge from drying beds was characterized and sulfuric acid was selected as the acidic leaching medium and effect of five variables were tested: acid concentration $(\mathrm{N})$, sludge weight $(\mathrm{g})$, mixing speed (rpm), temperature $\left({ }^{\circ} \mathrm{C}\right)$ and leaching time $(\mathrm{min})$ was studied. Moreover, the process efficiency was evaluated at different operating conditions. Then optimum conditions were applied to get maximum recovery for aluminum sulfate. Maximum recovery is $94.2 \%$ at acid concentration $1.5 \mathrm{~N}$, sludge weight $5 \mathrm{~g}$, mixing speed $60 \mathrm{rpm}$, temperature $60{ }^{\circ} \mathrm{C}$ and leaching time $40 \mathrm{~min}$.

Keywords: sludge, water treatment, aluminum sulfate, acidification, Recovery, leaching, aluminum.
\end{abstract}


J. Environ. Sci.

Institute of Environmental Studies and Research - AinShamsUniversity

\section{INTRODUCTION}

One of the most important problems of the $21^{\text {st }}$ century is the availability of clean drinking water, a resource important for our survival and development. Most of the fresh water bodies all over the world are being polluted due to unplanned urbanization, industrialization and anthropogenic activities (Singh et al., 2002). Surface water sources served as the best sinks for the discharge of domestic as well as industrial effluents. The unwise disposal of waste has caused immense problems not only to human beings but also to aquatic environment (Heberer, 2002).

Coagulation is the most common process used to remove suspended particles, colloids, organics, color and microorganisms from the drinking water supplies (Duan and Gregory, 2003 and Ghafari et al., 2009). Enormous quantities of water treatment plant sludge (WTS) are produced when coagulants are added to raw water. For example, water treatment plants produce annually 18,000 tons as dry solids from Ireland, 34,000 tons as dry solids from The Netherlands and 182,000 tons as dry solids from UK (Babatunde and Zhao, 2007), and more than million tons of wet WTS is produced by water works in Egypt. Globally, available literature estimates that 10,000 tons of waterworks sludge is produced daily (Dharmappa et al., 1997). Due to regulatory changes in the recent past, WTS now has to be disposed into landfills or through land application in developed countries. However, in developing countries, it is disposed into water bodies or sanitary sewers (Nair and Ahammed, 2013). WTS was discharged into water bodies is reported to be toxic to aquatic life (Muisa et al., 2011) Since the levels of 
pollutants in WTS are relatively low, as the best quality raw water sources are generally selected for drinking water production (Ishikawa et al., 2007), the reuse of WTS may be a feasible option. A number of research efforts have been made particularly in recent years to use WTS in many beneficial ways. Which include its uses in building and construction materials (Monteiro et al., 2008 and Pan et al., 2004), in wastewater treatment (Babatunde and Zhao, 2010; Moghaddam et al., 2010 and Nair and Ahammed, 2013) and for soil improvement (Hovsepyan and Bonzongo, 2009). Two different approaches have been tried for the metal use of WTS in water and wastewater treatment. In the first approach, coagulant is first recovered from WTS and is reused as a coagulant for the treatment of water and wastewater. In the second approach, wet/dry sludge itself is used as a coagulant or adsorbent for removal of different contaminants. Recovery of coagulant metal from WTS is an attractive option and has been reported by many researchers (Chen et al., 2012; Ishikawa et al., 2007 and Xu et al., 2009). Generally, four ways of coagulant recovery are employed for the WTS, which includes acidification, basification, ion exchanging, and membrane processes (Xu et al., 2009). Most of the studies reported recently used acidification for coagulant recovery due to high efficiency and low cost compared to other methods (Chen, et al., 2012; Huang, et al., 2010). Several factors are known to affect coagulant metal recovery from WTS by acidification. These include $\mathrm{pH}$ of the solution, mixing speed and intensity, mixing time, temperature and sludge content in the mixture (Chen, et al., 2012; and $\mathrm{Xu}$, et al., 2009). This work aims at 
producing aluminum sulfate from waterworks sludge using sulfuric acid under Egyptian conditions.

\section{EXPERIMENTAL}

\section{1- Materials:}

Alum sludge was collected from El-Shiekh Zayd water treatment plant at Giza, Egypt, treating water from river Nile using alum as the coagulant. The WTS samples were collected in polyethylene bags and were transported to the drinking water reference laboratory of Holding Company for water and wastewater, Cairo, Egypt. The sludge dried in a hot air oven at $105{ }^{\circ} \mathrm{C}$ for 24 $\mathrm{h}$, and crushed using a mortar and pestle, and a quantity of 1000 grams applied to $2 \mathrm{~mm}$ sieve and the fraction passing through was collected and used in the performed tests. The same batch of sludge was mixed and used in all the tests. Concentrations of relevant elements detected in the sludge are presented in Table 1. Beryllium (Be), Silver (Ag), Cadmium (Cd) and Molybdenum (Mo) were below the detectable limits. The WTS contains high proportions of $\mathrm{Al}$ and $\mathrm{Fe}$.The digested sludge solution was analyzed for metals using inductively-coupled plasma atomic emission spectrometry (ICPPerkin-Elmer optima 8300 dv) using US EPA method no. 200.7 (Martin, et al., 1992) and pH was measured using $\mathrm{pH}$ meter (Hach HQd Portable Meter)

\section{2-WTS characterization:}

In order to estimate the total metals in the WTS used, acid digestion carried out using US EPA method number 3050B (US EPA, 1996). Total volatile organic solids were measured by loss on ignition at $550 \circ \mathrm{C}$ 
(Santisteban. et al., 2004). The water content of collected WTS is determined through weighting $1 \mathrm{gm}$ of it then drying at $105{ }^{\circ} \mathrm{C}$ for 2 hours and reweighting it and calculating water content through the following equation (eq.1):

Water content $\%=\frac{\text { sludge weight before drying-sludge weight after drying }}{\text { sludge weight before drying }} \times 100$ (eq.1)

\section{3-Aluminum recovery}

Aluminum recovery from the sludge was carried out using a jar test apparatus (Velp Scientifica), and the five factors were tested during the recovery process then the solution was filtered and filtrate was analyzed for Al. All experiments were carried out in triplicates. The aluminum recovery was calculated as follows (eq. 2):

$\mathrm{Al}$ recovery efficiency $\%=\frac{A l \text { in supernatant after acidification }(\mathrm{mg} \mathrm{Al} / \mathrm{g} \text { dry sludge })}{A l \text { in raw sludge after acid digestion }(\mathrm{mg} \mathrm{Al} / \mathrm{g} \text { dry sludge })} \times 100$ (eq. 2$)$

Acidic leaching of Al (III) from the WTS sample was performed using sulfuric acid solutions at various concentrations, speed intensities, WTS weights, leaching times and temperatures. After leaching was complete, the solution was left to settle for 10 minutes then filtered on filter paper with pore size $0.45 \mu \mathrm{m}$, and the filtrate was subjected to (ICP- Perkin-Elmer optima $8300 \mathrm{dv}$ ) using US EPA method no. 200.7 (Martin, et al., 1992) to determine the $\mathrm{Al}(\mathrm{III})$ concentration. Each experiment was repeated two times and represented with average values.

\section{3-1-Effect of sulfuric acid concentrations (N) on $\mathrm{Al}$ (III) recovery:}

The effect of sulfuric acid concentration (N) on Al (III) recovery was studied using a set of samples that were prepared by adding $500 \mathrm{ml}$ of 2.0 , $1.5,1.0,0.5$, and $0.1 \mathrm{~N}$ sulfuric acid to $5 \mathrm{~g}$ WTS samples. Leaching was 
performed at $25{ }^{\circ} \mathrm{C}$ with the mixing speed set to $80 \mathrm{rpm}$ for 20 min leaching time. Samples were collected for analysis to determine the amount of soluble $\mathrm{Al}(\mathrm{III})$.

\section{3-2-Effect of WTS weight on Al (III) recovery:}

The effect of WTS weight on Al (III) leaching rate was studied using a set of samples that were prepared by adding $500 \mathrm{ml}$ of $1.0 \mathrm{~N}$ sulfuric acid to $5,10,15,20,25 \mathrm{~g}$ grinded WTS. Leaching was performed at $25{ }^{\circ} \mathrm{C}$ with the paddle speed set to $80 \mathrm{rpm}$ applying 20 min leaching time. Samples were collected for analysis to determine the amount of soluble Al (III).

\section{3-3 -Effect of Leaching time on $\mathrm{Al}$ (III) recovery:}

Leaching involved adding $5 \mathrm{~g}$ WTS samples to $500 \mathrm{ml}$ of $1.0 \mathrm{~N}$ sulfuric acid solution. Experiments were performed at temperature of $25 \circ \mathrm{C}$ with the paddle speed maintained at $80 \mathrm{rpm}$ and 10, 20, 30, 40, 50 min leaching periods. Samples were filtered and collected to determine the amount of soluble $\mathrm{Al}$ (III).

\section{3-4-Effect of temperature on $\mathrm{Al}$ (III) recovery:}

Leaching involved adding $5 \mathrm{~g}$ WTS samples to $500 \mathrm{ml}$ of $1.0 \mathrm{~N}$ sulfuric acid solution. Experiments were performed at temperatures of $25{ }^{\circ} \mathrm{C}, 40{ }^{\circ} \mathrm{C}$, and $60{ }^{\circ} \mathrm{C}$ with the stirring speed maintained at $80 \mathrm{rpm}$ and 20 min leaching time. Samples were filtered and collected to determine the amount of soluble $\mathrm{Al}(\mathrm{III})$. 


\section{3-5-Effect of mixing speed on Al (III) recovery:}

Leaching involved adding $5 \mathrm{~g}$ WTS samples to $500 \mathrm{ml}$ of $1.0 \mathrm{~N}$ sulfuric acid solution. Experiments were performed at temperature of $25{ }^{\circ} \mathrm{C}$ with the paddle speeds maintained at 20,40,60, 80 and $100 \mathrm{rpm}$ and 20 min leaching time. Samples were filtered and collected to determine the amount of soluble $\mathrm{Al}(\mathrm{III})$.

\section{3-6-Preparation of coagulant solution:}

An alum solution is prepared through applying the optimum conditions obtained above for maximum recovery which is $1.5 \mathrm{~N}, 5 \mathrm{~g}, 60 \mathrm{rpm}, 40 \mathrm{~min}$ and $60{ }^{\circ} \mathrm{C}$ for sulfuric acid concentration, WTS weight, paddle speed, leaching time and temperature respectively and a maximum recovery were reached by $94.2 \%$.

\section{RESULTS AND DISCUSSION}

\section{1-Sludge characteristics:}

The average values of $\mathrm{pH}$, water percentage and organic content of collected WTS were $7.7,86 \%$ and $25 \%$ respectively. Sludge characteristics were studied to determine aluminum metal coagulant concentration leaching. The major constituents of WTS were aluminum and iron which are almost the same as the composition of commercial aluminum sulfate which indicates that the main source of metals is commercial alum coagulant and no significant increase in metals occur from raw water. This encourages the recovery of aluminum metal coagulant from WTS without any accumulation for metals in the treated water. Metal analysis data is presented in table 1 . The 
water percent is $86 \%$, the dry sludge organic content is $25 \%$ and the major elements determined were aluminum $13.3 \%$, iron $2.2 \%$ and manganese $0.18 \%$. The difference in metal composition between sludge and commercial alum is due to the dissolution of small portion of metals in treated water and not settled with sludge.

Table 1: The WTS metals analysis (expressed by mg per gra Compared to commercial coagulant

\begin{tabular}{|c|c|c|c|c|c|c||c|}
\hline Metal & Al & Ba & Co & Cr & Cu & Fe & \multirow{2}{*}{} \\
\hline \hline Sludge & 133.4 & 0.13 & 0.02 & 0.13 & 0.05 & 22.1 & \\
\hline C.A.S & 160.7 & 0.15 & 0.02 & 0.17 & 0.06 & 27.8 & \\
\hline Metal & $\mathbf{L i}$ & $\mathbf{M n}$ & $\mathbf{N i}$ & $\mathbf{P b}$ & $\mathbf{S r}$ & $\mathbf{V}$ & $\mathbf{Z n}$ \\
\hline Sludge & 0.01 & 1.8 & 0.04 & 0.87 & 0.165 & 0.12 & 0.11 \\
\hline C.A.S & 0.02 & 2.31 & 0.04 & 1.06 & 0.22 & 0.16 & 0.13 \\
\hline
\end{tabular}

C.A.S: Commercial Aluminum sulfate

\section{2-Effect of different factors on the Al (III) recovery}

\section{$\underline{\text { 2-1-Influence of sulfuric acid concentration on leaching process }}$}

The effect of sulfuric acid concentration on leaching efficiency of Al (III) is presented in Figure 1. The $\mathrm{Al}$ (III) leaching increases with sulfuric acid concentration and it reaches $73.8 \%$ at $(1.5 \mathrm{~N})$ acid concentration and only slight increase is obtained by increasing sulfuric acid concentration to $(2.0 \mathrm{~N})$. Our results agree with (Chen et al., 2012) as they recorded that the $\mathrm{Al}(\mathrm{III})$ leaching ratio increases with sulfuric acid concentration. Also our findings agree with (Xu et al., 2009) who reported Al (III) leaching of $61-100 \%$ from WTS using acidification for $\mathrm{pH}$ range 1 - 3, which may be due to that acid 
added has recovered the maximum possible aluminum from WTS under the applied conditions according to the following equation:

$2 \mathrm{Al}(\mathrm{OH})_{3}(\mathrm{~s})+3 \mathrm{H}_{2} \mathrm{SO}_{4}(\mathrm{aq}) \rightarrow \mathrm{Al}_{2}\left(\mathrm{SO}_{4}\right)_{3}(\mathrm{aq})+6 \mathrm{H}_{2} \mathrm{O} \quad \Delta \mathrm{H}<0 \quad$ (eq. 3)

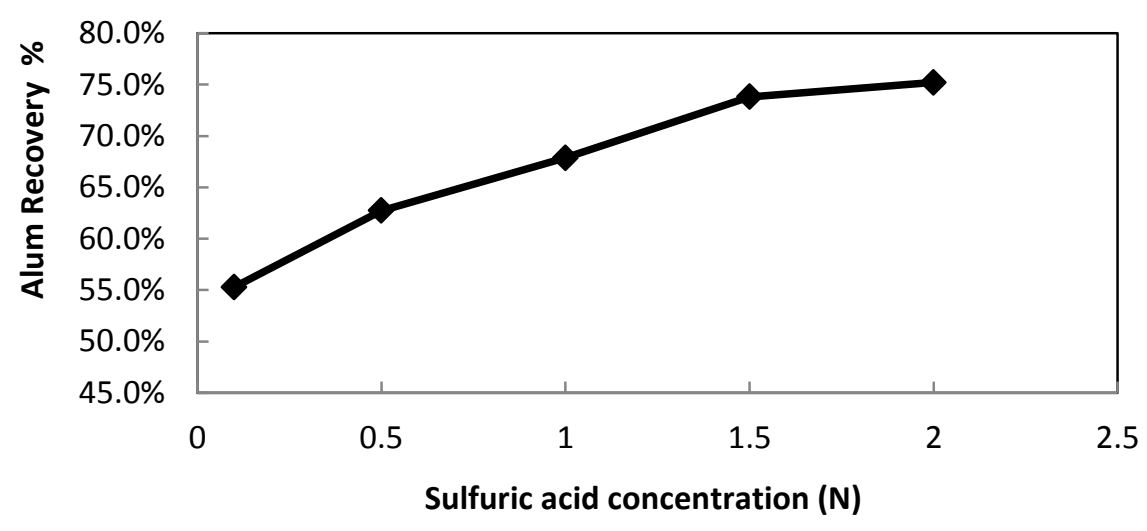

Figure 1: Effect of Sulfuric acid concentration on Alum Recovery percentage

\section{2-2-Impact of WTS weight on recovery of Al (III):}

The recovery rates of coagulant metal from WTS at different weights were measured and the results are presented in Figure 2. As shown that under the mentioned conditions the best recovery was $61.3 \%$ at $5 \mathrm{~g}$ sludge weight, which may be due to the more sludge applied more crowd is the solution, which decrease reaction opportunity between sludge particles $\mathrm{Al}(\mathrm{OH})_{3}$ and the acid. This result agrees with (Boaventura et al., 2000) who recorded the increase in leaching rates for aluminum, iron and manganese by decreasing sludge weight. 
J. Environ. Sci.

Institute of Environmental Studies and Research - AinShamsUniversity

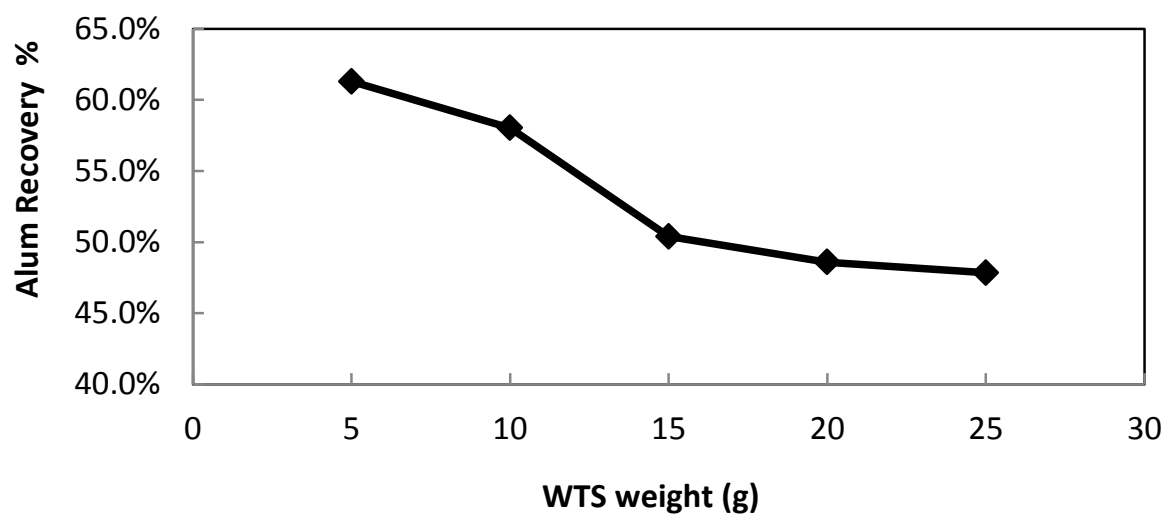

Figure 2: Effect of WTS weight (g) on Alum Recovery percentage

\section{2-4-Effect of temperature on leaching process}

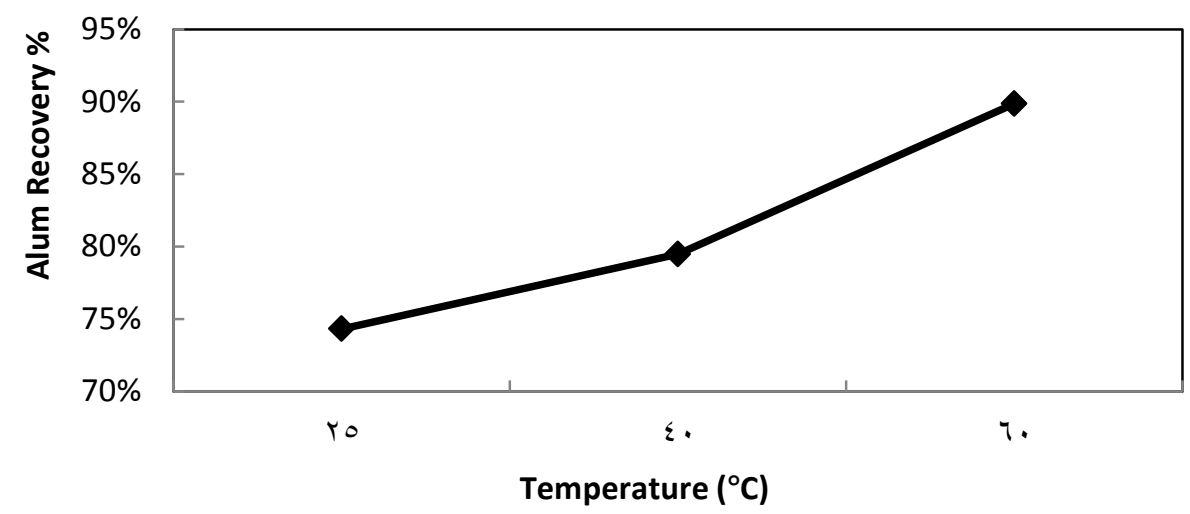

Figure 3: Effect of Temperature $\left({ }^{\circ} \mathrm{C}\right)$ on Alum Recovery percentage.

The extent of $\mathrm{Al}$ (III) ions leaching in experimental work is presented in Figure 3. At the applied conditions, the $\mathrm{Al}$ (III) leaching rate increases with temperature. Al (III) leaching efficiency increases recording maximum recovery of $89.9 \%$ at $60{ }^{\circ} \mathrm{C}$, which declare that $\mathrm{Al}$ (III) leaching rate is directly proportional to temperature; it may be due to increase in temperature 96 
elevate dissolution of aluminum in acid but not due to reaction thermodynamics (reaction is exothermic). Our results agreed with (Cheng et al., 2012) by applying different temperatures 10,40 and $70{ }^{\circ} \mathrm{C}$ and at a

particular reaction time, the $\mathrm{Al}$ (III) leaching rate increases with temperature. However, the reaction is exothermic more temperature push the reaction forward that may be due to the solubility of aluminum hydroxide increased by temperature. Our findings were compatible also with (Fan et al., 2013) who proved that leaching rate of $\mathrm{Ni}$ and $\mathrm{Co}$ in sulfuric acid solution is influenced much more by increasing temperature, the leaching rate of $\mathrm{Ni}$ and Co was $96.68 \mathrm{wt} \%$ when temperature elevated to $85^{\circ} \mathrm{C}$.

\section{2-5-Influence of mixing speed on leaching of Al (III)}

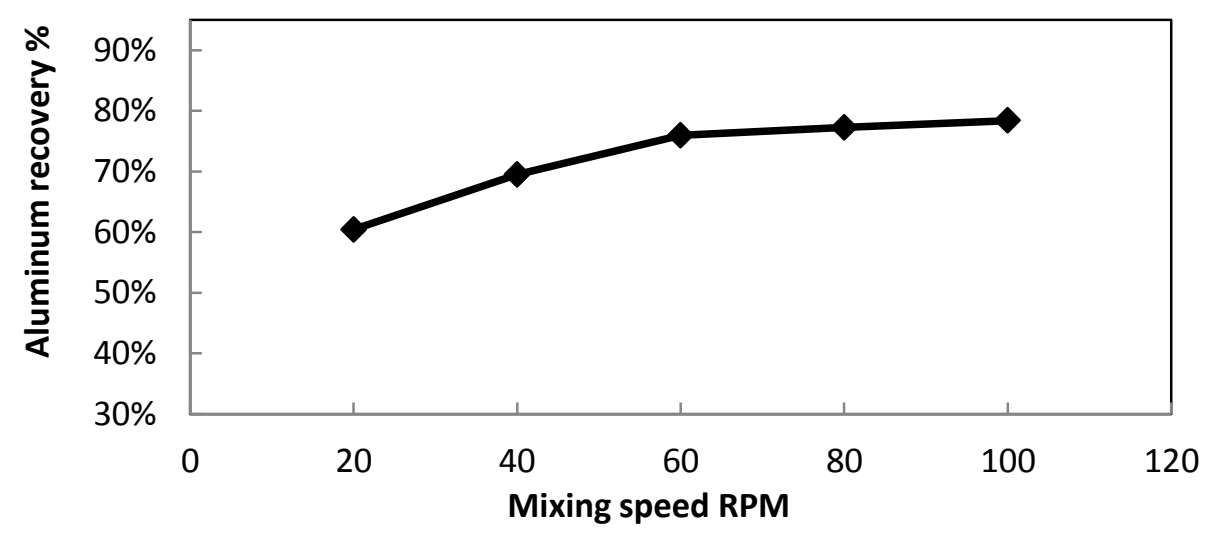

Figure 4: Effect of Mixing speed (RPM) on Alum Recovery percentage

The effect of mixing speed on Al (III) leaching efficiency is shown in Figure 4. As presented, the leaching efficiency of Al (III) increases with mixing speed below $60 \mathrm{rpm}$. However, mixing with higher speed than 60 
rpm, leaching efficiency does not show significant increase by increasing paddle speed. This phenomenon reveals that when stirring speed reaches a threshold, the thickness of the diffusion layer can no longer be effectively reduced. Therefore, the film diffusion control, does not affect Al (III) leaching rate (Cheng, et al, 2012). Our work agrees with (Cheng, et al, 2012) who applied mixing speeds (20-120 rpm), the leaching ratio of Al (III) increases with the mixing speed below $80 \mathrm{rpm}$; beyond $80 \mathrm{rpm}$, the leaching ratio does not increase with mixing speed. Also our results agree with (Gürmen, 2005) who also studied the effect of stirring speed on leaching rate of $\mathrm{Co}, \mathrm{Fe}$ and $\mathrm{Ni}$ and reported the increase of metals dissolution in acidic solutions by increasing mixing speeds.

\section{2-6-Influence of leaching time on recovery of $\mathrm{Al}$ (III)}

The effect of leaching time on the recovery rate is presented in Figure 5. As it is shown in Figure 5, the maximum recovery was $84.7 \%$. When the mixing time was $40 \mathrm{~min}$, however increasing the leaching time, over $40 \mathrm{~min}$ the recovery rate decreases slightly to $83.7 \%$ which may be due to the reformation of aluminum hydroxide due to the saturation of the solution. These results agree with (Cheng, et al., 2012) who found that Al (III) leaching increases with reaction time till 20 min but above $20 \mathrm{~min}$, the leaching reaction reaches a steady state that is not influenced by sulfuric acid concentration. Our findings also agree with (Fan et al., 2013) who reported that leaching rate of $\mathrm{Ni}$ and $\mathrm{Co}$ increase very quickly when leaching time increased up to 5 hours, leaching rate of $\mathrm{Ni}$ and Co can 
achieve above $96 \%$, and then although with the leaching time increasing, the leaching rate increased but slowly.

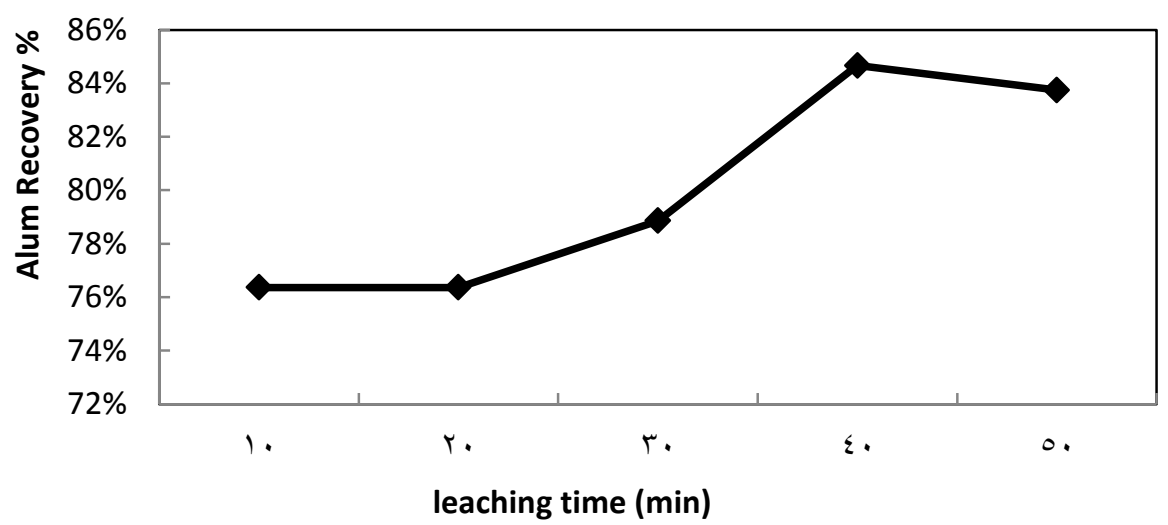

Figure 5: Effect of leaching time on alum recovery percentage

\subsection{Characteristics of prepared aluminum sulfate}

From the past studies, a maximum recovery, can be achieved which was $94.2 \%$ at acid concentration $1.5 \mathrm{~N}$, sludge weight $5 \mathrm{~g}$, mixing speed $60 \mathrm{rpm}$, temperature $60{ }^{\circ} \mathrm{C}$ and leaching time $40 \mathrm{~min}$. As shown in Table 2 the metals content in the prepared aluminum sulfate (P.A.S) is comparable to the commercial alum used in drinking water treatment, which refers to, there is no risk from the accumulation of metals in the recovered alum. As shown in Table 2 there is a slight increase in aluminum and iron and that may owed to; acidification process cannot make $100 \%$ recovery for aluminum and iron found in sludge, and there is a small proportion of iron and aluminum concentrations is found soluble in treated water. A comparison between characteristics of the recovered and the commercial alum is done through 
analysis of metal content and shown in Table 2. Sludge volume after acidification is reduced by $30 \%$ from the original volume.

Table 2: comparison between the metals analysis of prepared (P.A.S) and commercial aluminum sulfate expressed by $\mathrm{mg} / \mathrm{l}$

\begin{tabular}{|c|c|c|c|c|c|c|c|}
\hline & $\mathbf{A l}$ & $\mathbf{B a}$ & $\mathbf{C o}$ & $\mathbf{C r}$ & $\mathbf{C u}$ & $\mathbf{F e}$ & $\mathbf{L i}$ \\
\hline \hline P.A.S & 72.42 & 0.07 & 0.01 & 0.07 & 0.03 & 12.00 & 0.01 \\
\hline C.A.S & 80.32 & 0.08 & 0.01 & 0.08 & 0.03 & 13.31 & 0.01 \\
\hline & $\mathbf{M n}$ & $\mathbf{N i}$ & $\mathbf{P b}$ & $\mathbf{S r}$ & $\mathbf{V}$ & $\mathbf{Z n}$ & \\
\cline { 1 - 6 } P.A.S & 0.98 & 0.02 & 0.47 & 0.09 & 0.07 & 0.06 & \\
\cline { 1 - 6 } C.A.S & 1.08 & 0.02 & 0.52 & 0.10 & 0.07 & 0.07 & \\
\hline
\end{tabular}

P.A.S: Prepared Aluminum sulfate

C.A.S: Commercial Aluminum sulfate

\section{SUMMARY}

Coagulant metal recovery from waterworks sludge for re-use, though not a new concept remains a key option towards the reduction of chemical usage in the water treatment industry. In this work, the aluminum recovery from ElShiekh Zayd treatment plant sludge using acidification was studied, and optimum coagulant recovery was obtained at acid concentration $1.5 \mathrm{~N}$, sludge weight $5 \mathrm{~g}$, mixing speed $60 \mathrm{rpm}$, temperature $60^{\circ} \mathrm{C}$ and leaching time 40 min. The recovered aluminum could be reused for water and wastewater treatment, because it shows no great difference from commercial coagulant. Acidification also reduced sludge volume by $30 \%$, thus reducing sludge handling cost. 


\section{REFERENCES}

Babatunde, A. O. \& Zhao, Y. Q. (2007): Constructive approaches toward water treatment works sludge management: an international review of beneficial re-uses. Crit Rev Environ Sci Technol 37:129-164

Babatunde, A. O. \& Zhao, Y. Q. (2010): Leachability and leaching patterns from aluminium-based water treatment residual used as media in laboratory-scale engineered wetlands. Environ Sci Pollut Res 17: $1314-1322$

Boaventura, R. A. R.; António, A. S. D. \& Almeida, M. F. (2000): Aluminum recovery from water treatment sludges, in: IV International Conference, Water Supply and Water Quality, Kraków-Poland, September 11-13, 1-4.

Chen, Y. J., Wang, W. M., Wei, M. J., Chen, J. L., He, J. L., Chiang, K. Y. \& $\mathrm{Wu}, \mathrm{C}$. C. (2012): Effect of Al-coagulant sludge characteristics on the efficiency of coagulant recovery by acidification. Environ Tech 33:2525-2530

Cheng, W. P., Fu, C. H., Chen, P. H., \& Yu, R. F. (2012): "Dynamics of aluminum leaching from water purification sludge." Journal of hazardous materials 217: 149-155.

Dharmappa, H. B., Hasia, A. \& Hagare, P. (1997): Water treatment plant residuals management. Water Sci Technol 35:45-56

Duan, J. \& Gregory, J. (2003): Coagulation by hydrolysing metal salts. Adv Colloid Interface Sci 100-102:475-502

Fan, X.; Xing, W.; Dong, H., Zhao, J.; Wu, Y., Li, B.; Tong W. \& Wu, X. (2013): Factors research on the influence of leaching rate of nickel and cobalt from waste super-alloys with sulfuric acid. International Journal of Nonferrous Metallurgy, 2013, 2, 63-67

Ghafari, S., Aziz, H. A., Hasnain, M. I. \& Zinatizadeh, A. K. (2009): Application of response surface methodology (RSM) to optimize coagulation flocculation treatment of leachate using poly aluminum chloride (PAC) and alum. J Hazard Mater 163:650-656 
Gürmen, S. (2005): Recovery of nano-sized cobalt powder from cemented carbide scrap. Turkish Journal of Engineering and Environmental Sciences, 29 (6), 343-350.

Heberer, T. (2002): Occurrence, fate, and removal of pharmaceutical residues in the aquatic environment: a review of recent research data. Toxicology Letters, 131, 5-17

Hovsepyan, A. \& Bonzongo, J. C. J. (2009): Aluminium drinking water treatment residuals (Al-WTR) as sorbent for mercury: implications for soil remediation. J Hazard Mater 164:73-80

Huang, S., Chen J. L., Chiang, K. Y. \& Wu, C. C. (2010): Effects of acidification on dewaterability and aluminum concentration of alum sludge. Sep Sci Tech 45:1165-1169

Ishikawa, S., Ueda, N., Okumura, Y., Lida, Y. \& Baba, K. (2007): Recovery of coagulant from water supply plant sludge and its effect on clarification. J Mater Cycles Waste Manag 9:167-172

Martin, Theodore, D., Carol, A. Brockhoff, John, T. Creed, \& Stephen, E. Long. (1992): "Determination of metals and trace elements in water and wastes by inductively coupled plasma-atomic emission spectrometry." In Methods for Determination of Metals, 33-91.

Moghaddam, S. S., Moghaddam, M. R. A. \& Arami, M. (2010): Coagulation/ flocculation process for dye removal using sludge from water treatment plant: optimization through response surface methodology. J Hazard Mater 175:651-657

Monteiro, S. N., Alexandre, J., Margem, J. I., Sanchez, R. \& Vieira, C. M. F. (2008): Incorporation of sludge waste from water treatment plant into red ceramic. Constr Build Mater 22:1281-1287

Muisa, N., Hoko, Z. \& Chifamb, P. (2011): Impacts of alum residues from Morton Jaffray Water Works on water quality and fish, Harare, Zimbabwe. Phys Chem Earth Parts A/B/C 36:853-864

Nair, A. T. \& Ahammed, M. M. (2013): The reuse of water treatment sludge as a coagulant for post-treatment of UASB reactor treating urban wastewater. J Clean Prod. 
Pan, J. R., Huang, C. \& Lin, S. (2004): Reuse of fresh water sludge in cement making. Water Sci Technol 50:183-188

Santisteban, J.I., R. Mediavilla, E. López-Pamo, C.J. Dabrio, M.B.R. Zapata, M.J.G. García, S. Castaño, \& P.E. Martínez-Alfaro (2004): Loss on ignition: a qualitative or quantitative method for organic matter and carbonate mineral content in sediments? Journal of Paleolimnology 32: 287-299.

Singh, S. P., Pathak, Deepa \& Singh, Rashmi: (2002): Hydrobiological Studies of two ponds of Satna(M.P.), Eco.Environmental and Conservation, Vol.8(3), Pg. no. 289-292.

US EPA (1996): Acid digestion of sediment, sludge and soils. Method 3050B, second edition. US Environmental Protection Agency, US Governmental Printing Office, Washington DC.

Xu, G. R., Yan, Z. C., Wang, Y. C. \& Wang, N. (2009): Recycle of alum recovered from water treatment sludge in chemically enhanced primary treatment. J Hazard Mater 161:663-669 


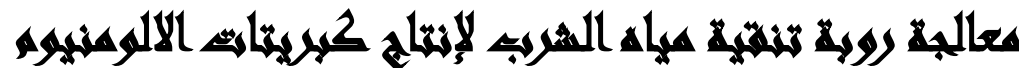

[०]

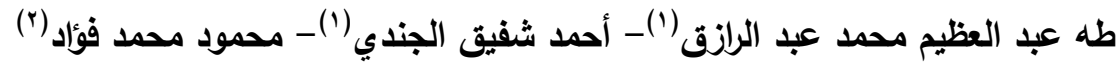

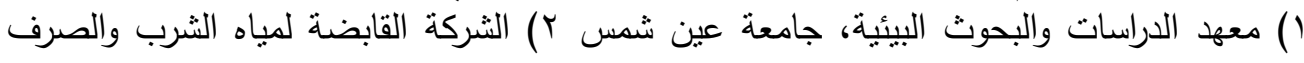

\section{المستخلصى}

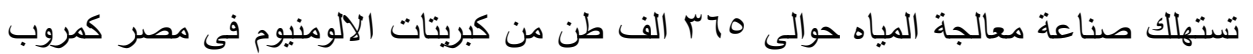

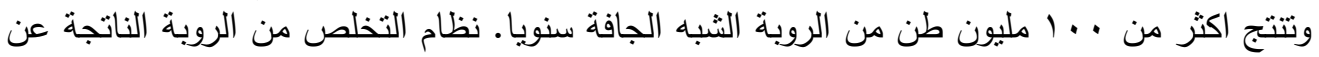

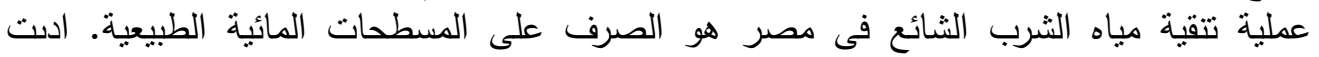

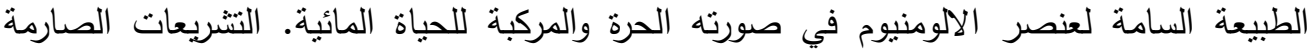
والقواعد المنظمة لحماية البيئية بشان التخلص من الرئية الرية الناتجة عن الثبة في المسطحات المائية،

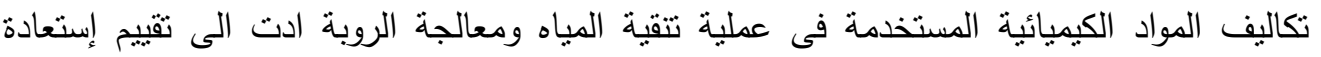

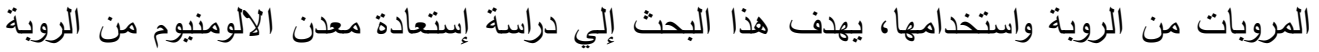

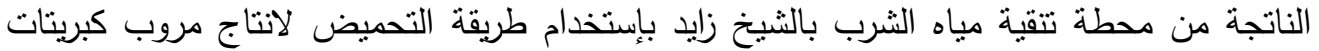

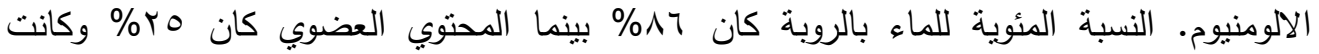

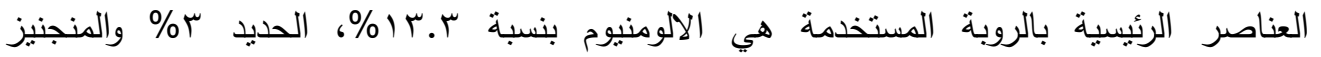

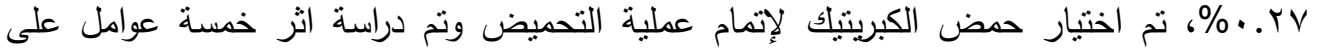

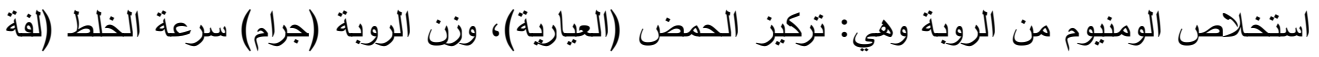

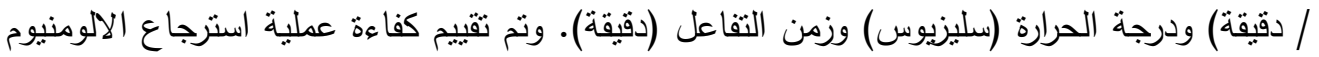

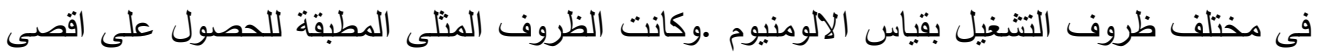

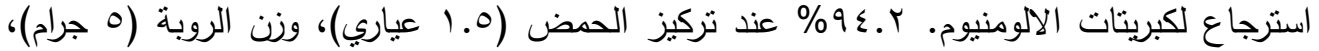

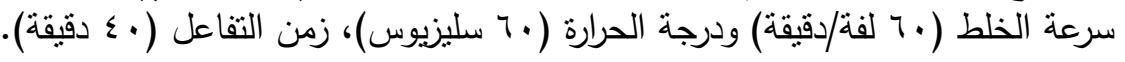

